\title{
Uneven recovery patterns of compromised health-related quality of life (EQ-5D-3 L) domains for breast Cancer survivors: a comparative study
}

Jonghan Yu', Woo-Seung Son², Sae Byeol Lee ${ }^{3}, \|$ Young Chung ${ }^{3}$, Byung Ho Son ${ }^{3}$, Sei Hyun Ahn³, Min-Woo Jo $\mathrm{2}^{2^{*}}$ and Jong Won Lee 3* $^{3^{*}}$

\begin{abstract}
Background: Although several studies have evaluated health-related quality of life ( $\mathrm{HRQOL}$ ) in breast cancer survivors, few have compared HRQOL between breast cancer survivors and an age-matched general population in terms of improvement patterns according to time after surgery. Thus, we compared the postoperative changes in HRQoL in breast cancer survivors with those of age-matched general population groups using the EuroQoL fivedimension three-level questionnaire (EQ-5D-3 L).

Methods: EQ-5D-3 L questionnaires were obtained from 686 breast cancer survivors during follow-up visits. They were divided into five groups according to time after surgery: 0-5 months, 6-11 months, 12-35 months, 36-59 months, and $\geq$ 60 months. Their EQ-5D-3 L data, covering five dimensions (mobility, self-care, usual activities, pain/discomfort, and anxiety/depression), were compared with those of age-matched general population groups.

Results: The mean EQ-5D-3 L index of breast cancer survivors was high in group with longer time after surgery and the mean EQ-5D-3 L index of breast cancer group over 5 years after surgery was similar to that of an age-matched general population ( 0.919 vs $0.928, p=0.305$ ). Although there were deficits in all dimensions of breast cancer survivors, motility eventually exceeded that of general population groups and self-care and usual activities of groups over 3 years after surgery matched those of general population however, pain/discomfort and anxiety/depression of survivors over 5 years after surgery remained worse than those of the general population $(p=0.028, p<0.001)$.

Conclusions: Motility, self-care, and usual activities decreased in the early postoperative period for breast cancer survivors but showed recovery after 3 years. However, pain/discomfort and anxiety/depression remained poorer in these patients than in the general population for many years.
\end{abstract}

Keywords: Breast cancer, Quality of life, EQ-5D-3 L, General population

\section{Background}

Breast cancer is the most common cancer in women worldwide [1], but its mortality has decreased due to advances in diagnostic tools and multimodal treatments.

\footnotetext{
* Correspondence: mdjominwoo@gmail.com; jjjongwr@hanmail.net Min-Woo Jo and Jong Won Lee were co-corresponding authors. ${ }^{2}$ Department of Preventive Medicine, University of Ulsan College of Medicine, 86 Asanbyeongwon-gil, Songpa-gu, Seoul 138-736, South Korea ${ }^{3}$ Department of Surgery, University of Ulsan College of Medicine, Asan Medical Center, 86 Asanbyeongwon-gil, Songpa-gu, Seoul 138-736, South Korea

Full list of author information is available at the end of the article
}

Accordingly, breast cancer patients experience various health-related quality of life (HRQoL) changes during their cancer journey, which encompasses diagnosis, treatment, long-term follow-up, and recurrence. Improved disease-free and overall survival outcomes, which are the most important achievements in breast cancer management, have led clinicians to focus intensively on the HRQoL of breast cancer survivors.

Many studies have evaluated the HRQoL of breast cancer survivors. Soon after diagnosis, there is a deficit in emotion and cognition, predominantly in younger breast cancer

(c) The Author(s). 2018 Open Access This article is distributed under the terms of the Creative Commons Attribution 4.0 International License (http://creativecommons.org/licenses/by/4.0/), which permits unrestricted use, distribution, and reproduction in any medium, provided you give appropriate credit to the original author(s) and the source, provide a link to the Creative Commons license, and indicate if changes were made. The Creative Commons Public Domain Dedication waiver (http://creativecommons.org/publicdomain/zero/1.0/) applies to the data made available in this article, unless otherwise stated. 
patients, and even many years after treatment, breast cancer survivors can have financial difficulties and show deficits in self-reported cognition, pain, and physical and social function [2-5]. Some studies reported improvements in the HRQoL of breast cancer survivors after treatment [6-12] and a long-term follow-up study showed no clinically important differences between breast cancer survivors and controls in physical functioning, fatigue, social and role functioning, emotional functioning, and symptoms [12]. Although some studies have reported on the long-term quality of life for breast cancer survivors, there have been few comparisons with the general population $[6,13,14]$. There have been several interpretations of the HRQoL of breast cancer survivors, which had various limitations according to method, follow-up period, study population, and comparison with control groups.

This investigation was conducted using the EuroQoL five-dimension three-level questionnaire (EQ-5D-3 L) as the HRQoL instrument. This tool consists of five simple questions but its validity as a HRQoL measurement approach has been confirmed for many disease areas [15-17]. In addition, the EQ-5D-3 L index can also help to later assess the efficiency of each intervention by being used as a utility score. More importantly, in Korea, the EQ-5D-3 L results of the general population have been obtained through the 5th Korea Health and $\mathrm{Nu}-$ trition Examination Survey (KNHANES) data. Therefore, the EQ-5D-3 L is an appropriate tool for comparing the HRQoL of Korean breast cancer survivors with that of a general population.

In our current study therefore, we investigated the time-specific HRQoL after breast cancer treatment over time using the EQ-5D-3 L and compared the results with that of a large age-matched general population group. We also evaluated when the HRQoL of breast cancer survivors showed recovery and the characteristic patterns in HRQoL according to EQ-5D-3 L dimension after treatment.

\section{Methods}

\section{Study design and subject recruitment}

This study encompassed a cross-sectional survey. A total of 686 breast cancer patients enrolled at Asan Medical Center completed the HRQoL questionnaire during a regular follow-up visit from January 2012 to June 2012. They were disease-free at the time of the survey. Their median follow-up was 42 (1-244) months. An age-matched control group $(N=2744)$ was obtained from the 5 th Korea Health and Nutrition Examination Survey (KNHANES) data for all breast cancer patients $(N=686)$ on a $4: 1$ basis. The KNHANES is a national, cross-sectional health examination survey and the 5th survey was conducted from 2010 2012. The KNHANES uses a complex, stratified, multistage probability cluster sampling to recruit a representative sample of the non-institutionalized population in
Korea. It reports prevalence of various chronic conditions such as hypertension and health status using self-rated health and EQ-5D-3 L $[18,19]$. This study was approved by the Institutional Review Board of Asan Medical Center. Informed consent was obtained from all participants.

\section{Measures}

HRQoL refers to quality of life related to health conditions and perceived health conditions [20]. Generally, HRQoL is measured by a survey instrument, of which the EuroQoL EQ-5D-3 L, developed by the EuroQoL group, is the most popular. In addition, the EQ-5D-3 L was adopted by the KNHANES so national representative data were available in Korea. It consists of five dimensions: mobility, self-care, usual activities, pain/discomfort, and anxiety/depression. Each dimension is assessed on a three-point ordinal scale: no problem, some or moderate problems, and extreme problems [16]. The EQ-5D-3 L has frequently been used to measure HRQoL in the general population and in patients with different diseases such as stroke [15] and diabetes [17]. This tool also shows validity and reliability for breast cancer patients in Korea [21]. In addition, valuation sets to calculate the utility weight of the EQ-5D-3 L index score have been suggested in many countries, including England [22], the United States [23], Japan [24], and Korea [25] using the time trade-off method.

\section{Statistical methods}

Chi-square analyses were applied to identify proportions for various characteristics by follow-up duration after surgery, to analyze differences in EQ-5D-3 L indices between two groups according to follow-up duration after surgery, and to examine problem reporting in each dimension between two groups.

\section{Results \\ Characteristics of the study populations according to time after surgery}

More than half of the current study patients had been diagnosed with early-stage breast cancer (stage I: $52.2 \%$ ) and most had received breast-conserving surgery $(62.2 \%)$ and radiation therapy $(68.8 \%)$. Over $80 \%$ of these patients had endocrine therapy and about half had chemotherapy. For the largest proportion of patients, more than 5 years had elapsed since the surgery (32.9\%). When breast cancer patients were divided according to time after surgery, the patients in the longer months after surgery were older $(p<0.001)$ and had a lower level of education $(p=0.014)$ and early stage $(p=0.042)$. In addition, a higher proportion underwent mastectomy; thus, in this group, there was a low proportion of patients who had radiation therapy. Patients in the 3 to 5 years after surgery group were the least likely to have 
undergone chemotherapy (39.4\%) and showed the highest proportion of endocrine therapy (91.1\%) (Table 1).

EQ-5D index changes in breast cancer survivors according to time after surgery and a comparison of EQ-5D-3 L dimensions between groups

The EQ-5D indices of the breast cancer groups until 59 months after surgery were lower than those of the age-matched general population groups (Table 2). However, the EQ-5D index of the breast cancer group $\geq 60$ months after surgery was similar to that of the age-matched general population group ( 0.919 vs 0.928 , $p=0.305)$ (Table 2 and Fig. 1).
A comparison of the proportion of individuals indicating a problem in the breast cancer and age-matched general population groups according to the five dimensions of the EQ-5D revealed that the breast cancer group within 6 months after surgery was more likely to indicate a problem than the age-matched general population group in all dimensions. In particular, over half of the patients in the immediate postoperative period expressed a problem in the pain/discomfort (64.1\%) and anxiety/depression (53.8\%) dimensions. However, the proportion of breast cancer group survivors indicating a problem lowered in all aspects as time passed after surgery.

Interestingly, the breast cancer group at 36-59 months and $\geq 60$ months after surgery was significantly less likely

Table 1 Characteristics of patients group which was divided by time after surgery

\begin{tabular}{|c|c|c|c|c|c|c|c|c|c|c|c|}
\hline \multirow[t]{2}{*}{ Time after surgery, month } & \multicolumn{2}{|c|}{$0-5$} & \multicolumn{2}{|c|}{$6-11$} & \multicolumn{2}{|c|}{$12-35$} & \multicolumn{2}{|c|}{$36-59$} & \multicolumn{2}{|l|}{$60-$} & \multirow[b]{2}{*}{$p$-value } \\
\hline & $\mathrm{N}$ & $\%$ & $n$ & $\%$ & $n$ & $\%$ & $n$ & $\%$ & $n$ & $\%$ & \\
\hline Age at survey, year & & & & & & & & & & & $<0.001$ \\
\hline Mean $\pm S D^{a}$ & \multicolumn{2}{|c|}{$48.9 \pm 9.7$} & \multicolumn{2}{|c|}{$49.1 \pm 8.3$} & \multicolumn{2}{|c|}{$49.5 \pm 8.6$} & \multicolumn{2}{|c|}{$49.5 \pm 6.8$} & \multicolumn{2}{|c|}{$53.6 \pm 7.9$} & \\
\hline $20-49$ & 21 & 53.8 & 53 & 57.6 & 74 & 49.7 & 89 & 49.4 & 60 & 26.5 & \\
\hline $50-$ & 18 & 46.2 & 39 & 42.4 & 75 & 50.3 & 91 & 50.6 & 166 & 73.5 & \\
\hline \multicolumn{12}{|l|}{ Age at diagnosis, year } \\
\hline Mean $\pm S D^{a}$ & \multicolumn{2}{|c|}{$48.2 \pm 9.7$} & \multicolumn{2}{|c|}{$48.1 \pm 8.3$} & \multicolumn{2}{|c|}{$47.1 \pm 8.3$} & \multicolumn{2}{|c|}{$45.2 \pm 6.8$} & \multicolumn{2}{|c|}{$45.2 \pm 8.1$} & \\
\hline Level of Education & & & & & & & & & & & 0.014 \\
\hline$\leq$ middle school & 10 & 26.3 & 12 & 13.0 & 20 & 13.5 & 15 & 8.3 & 40 & 17.7 & \\
\hline$\leq$ high school & 12 & 31.6 & 42 & 45.7 & 71 & 48.0 & 68 & 37.8 & 91 & 40.3 & \\
\hline$\geq$ college & 16 & 42.1 & 38 & 41.3 & 57 & 38.5 & 97 & 53.9 & 95 & 42.0 & \\
\hline Living with spouse & & & & & & & & & & & 0.160 \\
\hline Yes & 31 & 79.5 & 75 & 81.5 & 121 & 81.2 & 161 & 89.4 & 184 & 81.4 & \\
\hline No & 8 & 20.5 & 17 & 18.5 & 28 & 18.8 & 19 & 10.6 & 42 & 18.6 & \\
\hline Stage (AJCC 7th) & & & & & & & & & & & 0.042 \\
\hline । & 20 & 51.3 & 42 & 45.7 & 78 & 52.7 & 111 & 61.7 & 107 & 47.6 & \\
\hline$\|$ & 16 & 41.0 & 38 & 41.3 & 50 & 33.8 & 61 & 33.9 & 93 & 41.3 & \\
\hline III & 3 & 7.7 & 12 & 13.0 & 20 & 13.5 & 8 & 4.4 & 25 & 11.1 & \\
\hline Type of Surgery & & & & & & & & & & & $<0.001$ \\
\hline Breast conserving surgery & 28 & 71.8 & 64 & 69.6 & 116 & 77.9 & 115 & 63.9 & 104 & 46.0 & \\
\hline Mastectomy & 11 & 28.2 & 28 & 30.4 & 33 & 22.1 & 65 & 36.1 & 122 & 54.0 & \\
\hline Radiotherapy & & & & & & & & & & & $<0.001$ \\
\hline Done & 28 & 71.8 & 69 & 75.0 & 125 & 83.9 & 121 & 67.2 & 129 & 57.1 & \\
\hline Not done & 11 & 28.2 & 23 & 25.0 & 24 & 16.1 & 58 & 32.2 & 96 & 42.5 & \\
\hline Chemotherapy & & & & & & & & & & & $<0.001$ \\
\hline Done & 23 & 59.0 & 62 & 67.4 & 87 & 58.4 & 71 & 39.4 & 143 & 63.3 & \\
\hline Not done & 16 & 41.0 & 30 & 32.6 & 62 & 41.6 & 109 & 60.6 & 83 & 36.7 & \\
\hline Endocrine therapy & & & & & & & & & & & $<0.001$ \\
\hline Done & 29 & 74.4 & 66 & 71.7 & 112 & 75.2 & 164 & 91.1 & 200 & 88.5 & \\
\hline Not done & 10 & 25.6 & 26 & 28.3 & 37 & 24.8 & 16 & 8.9 & 26 & 11.5 & \\
\hline
\end{tabular}

${ }^{a}$ SD standard deviation 
Table 2 Comparison of EQ-5D index according to time after surgery between breast cancer patient and general population

\begin{tabular}{|c|c|c|c|c|c|c|c|}
\hline \multirow{3}{*}{ BC group according to time after surgery, month } & \multicolumn{3}{|c|}{$\mathrm{BC}^{\mathrm{a},}(\mathrm{N}=686)$} & \multicolumn{3}{|c|}{ Age-matched $G P^{b},(N=2744)$} & \multirow[b]{3}{*}{$p$-value } \\
\hline & \multirow[b]{2}{*}{$\mathrm{N}$} & \multicolumn{2}{|c|}{ EQ-5D index score } & \multirow[b]{2}{*}{$\mathrm{N}$} & \multicolumn{2}{|c|}{ EQ-5D index score } & \\
\hline & & Mean & SD & & Mean & SD & \\
\hline $0-5$ & 39 & 0.862 & 0.108 & 156 & 0.952 & 0.078 & $<0.001$ \\
\hline $6-11$ & 92 & 0.902 & 0.081 & 368 & 0.956 & 0.084 & $<0.001$ \\
\hline $12-35$ & 149 & 0.909 & 0.093 & 596 & 0.947 & 0.110 & $<0.001$ \\
\hline $36-59$ & 180 & 0.924 & 0.075 & 720 & 0.944 & 0.102 & 0.010 \\
\hline $60-$ & 226 & 0.919 & 0.093 & 904 & 0.928 & 0.124 & 0.305 \\
\hline
\end{tabular}

${ }^{\mathrm{a}} B C$ Breast cancer survivors, ${ }^{\mathrm{b}} G P$ General population

to indicate a problem in the mobility dimension than the age-matched general population groups $(5.6 \%$ vs $12.8 \%$, $p=0.006 ; 10.6 \%$ vs $17.5 \%, p=0.012$ ). In the self-care and usual activities dimensions, breast cancer group over 3 years after surgery and age-matched general population showed similar proportions in a problem category, but a problem was indicated by a high proportion in all breast cancer group for the pain/discomfort and anxiety/ depression dimensions (Table 3, Fig. 2).

\section{Discussion}

The EQ-5D index of the breast cancer group in our current study at $\geq 60$ months after surgery was similar to that of an age-matched general population group. The dimension of mobility was significantly better in breast cancer groups over 36 months after surgery than in age-matched general population groups, whereas the self-care and usual activities dimensions were similar. However, the categories of pain/ discomfort and anxiety/depression were poorer than in the matched general population groups, with the deficits sustained over 5 years after surgery.

Unlike our results, Stover et al. showed the decrements of survivors within 6 months of diagnosis generally improved in QOL (pain, social functioning, physical

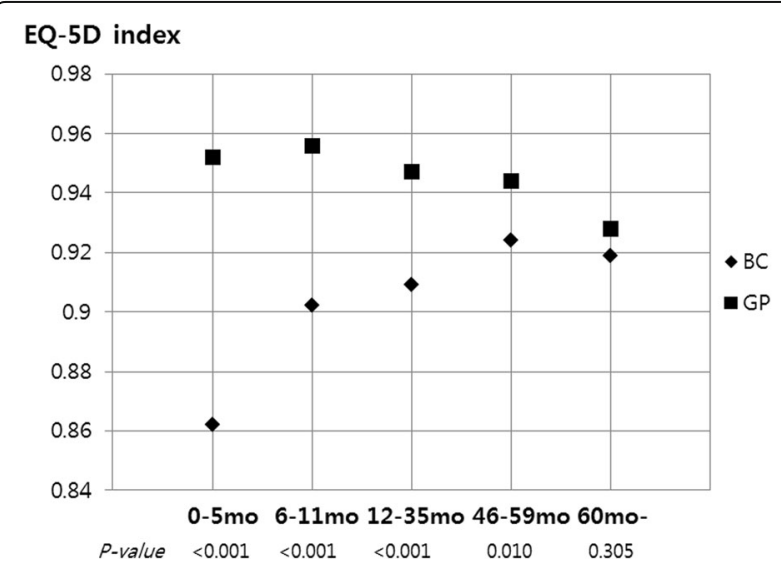

Fig. 1 EQ-5D index changes according to time of surgery in breast cancer patients and general population (BC: Breast cancer survivors; GP:General population) functioning, etc) after 12 months in 65 years and older American breast cancer patients [26]. However, considering that mean age of all Korean patients groups in this study was under 55 years, the recovery time and patterns of deficit after cancer treatment may be different depending on race and age.

There was a significant difference in the EQ-5D index among the groups according to time after surgery. As the time after surgery was longer, the EQ-5D index was higher and the HRQoL level of the breast cancer group over 5 years after surgery reached that of the age-matched general population group. In Table 2, the EQ-5D index at each domain was similar between breast cancer group and age-matched general population. And we can consider minimally important difference as the effect size in EQ-5D index results. Minimally important difference (MID) utility was various on diseases or other conditions but it is generally reported from $0.028-0.124[27,28]$. This result showed under 0.020 of MID between breast cancer over 3 years after surgery and age-matched general population. It was that there was no significant difference of the HRQoL level between two groups.

However, the mean age at the survey of the group with a long follow-up time ( $\geq 5$ years) after surgery was older than that of the other breast cancer groups and older people generally have a lower EQ-5D index than young people. Therefore, their index was expected to be lower than that of the other follow-up period groups. Against our expectations, the older group with a long follow-up time after surgery had a higher EQ-5D index than other younger groups with a short follow-up time after surgery. In addition, the group with a long follow-up time had more patients who underwent mastectomy and chemotherapy than the short-term follow-up groups. Thus, we expected patients in the long follow-up time group to show a low EQ-5D index. Mastectomy is associated with lower psychological well-being and overall quality of life than breast-conserving therapy even many years after treatment [6] and because chemotherapy can lead to the development of acute symptoms such as vomiting, fatigue, and alopecia, it has a negative impact on HRQoL [29]. Other systematic reviews showed that 


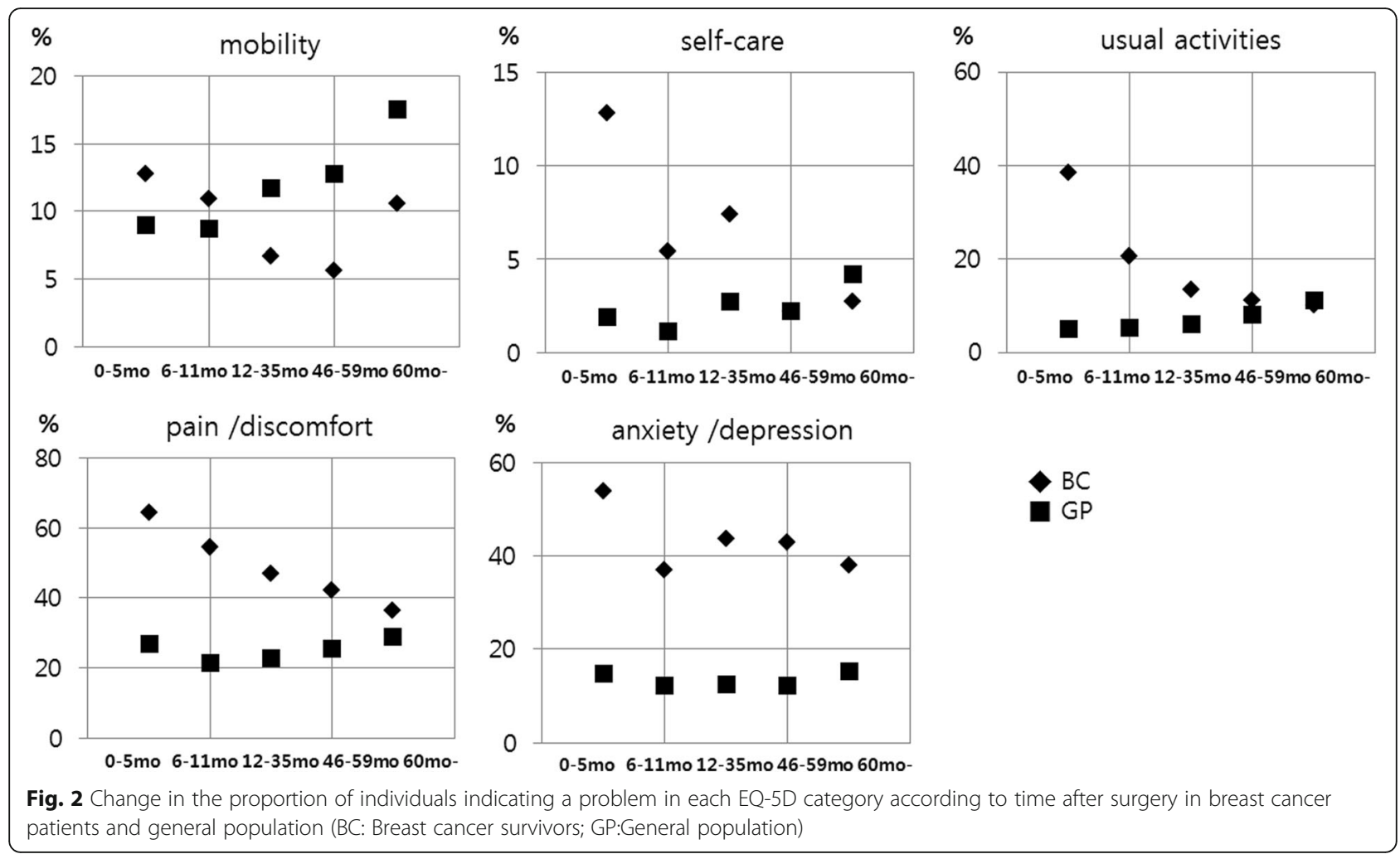

past chemotherapy was one of the strongest significant predictors of a poor quality of life [14,30]. However, survivors with a long follow-up time had a high score that was similar to that of the age-matched general population group. This mismatched result may be because the time and adaptation after treatment seemed to have a greater effect on the HRQoL of patients than age, diagnosis, and treatment, which generally affect HRQoL. Therefore, psychologic adaptation during the time after surgery may be crucial to explaining the improving HRQoL of cancer patients.

One interesting aspect of this study was that the proportion of patients indicating a problem in the dimension of mobility in the breast cancer group at 36-59 months and $\geq$ 60 months after surgery was significantly lower than in the age-matched general population groups. In other words, physical improvement and adaptation seemed to influence the gradual increase in HRQoL in breast cancer survivors. Increased physical activity after treatment has previously been positively associated with psychosocial well-being and HRQoL in breast cancer survivors [31]. In addition, exercise has beneficial effects on the HRQoL of cancer survivors, as assessed at various follow-up times [32].

Despite of the high EQ-5D index, assessment of the proportion of individuals indicating a problem showed different outcomes according to EQ-5D dimension. In the mobility dimension, the breast cancer group over 3 years after surgery were less likely to indicate a problem than the age-matched general population group, as discussed above, and breast cancer group after 3 years and age-matched general population showed the similar proportion of individuals with a problem in the usual activity and self-care dimensions. In terms of pain/discomfort and depression/ anxiety, although the proportion of individuals indicating a problem slowly decreased, the restriction persisted, even over 5 years after surgery. That is, breast cancer survivors experienced showed the recovery of HRQoL related to physical health up to that of the general population. However, they were likely to still have a low HRQoL level in pain and psychological aspects. Previous work also showed that deficits in such aspects as emotion or cognition persisted for many years in women with breast cancer [2] and some studies reported that breast cancer survivors experienced relative declines in HRQoL, even many years after diagnosis $[3,4]$. This result suggested that soon after an operation, a physical intervention such as mobility rehabilitation and regular exercise is needed to improve the HRQoL of breast cancer patients but intervention for and psychological support and pain management should consistently be provided to patients for a long time after surgery.

This study has the limitations of a cross-sectional study. This was a cross-sectional survey at one healthcare system vs. national survey for general population and we could not identify results based on longitudinal data in the same patient cohort. And there are many factors such as gender, age, education level, income that can affect the quality of 


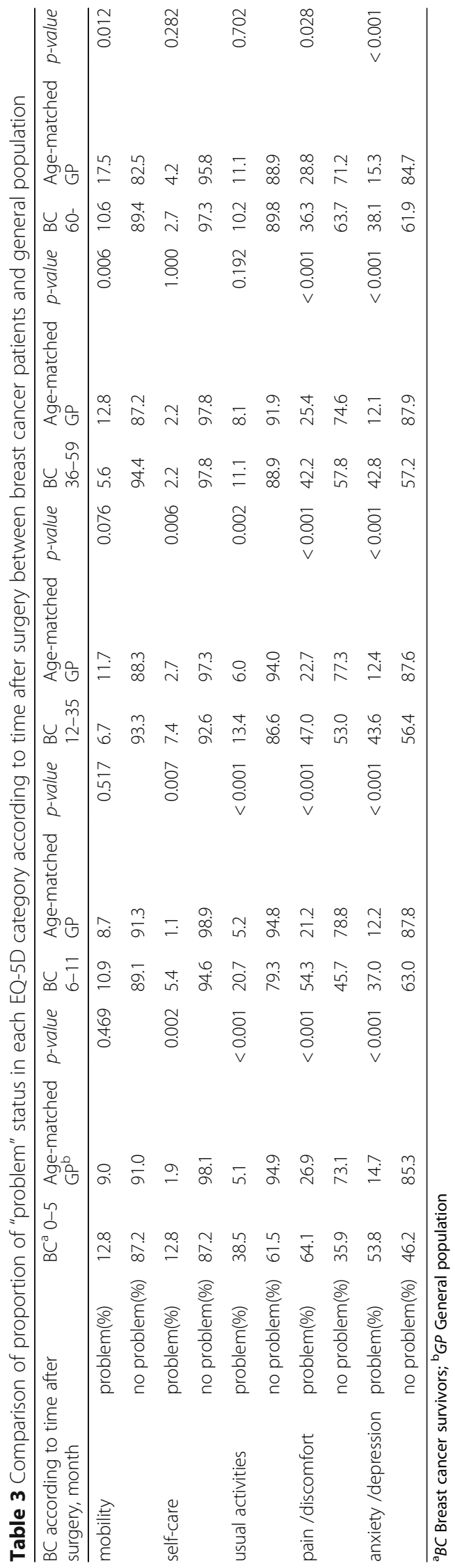


life. Because all of the patients were female, we did not consider gender in this study. Age was used as a factor. However, other factors were not taken into consideration. This point is also a limitation of this study.

However, this assessment was conducted in large-scale breast cancer patient groups and an age-matched Korean general population as a healthy control group, only enrolled patients with a long postoperative follow-up time, and provided the HRQoL of breast cancer survivors according to various times from surgery, comparing the data with those of age-matched general population groups. Therefore, these outcomes revealed the change of HRQoL according to EQ-5D dimension and which level of the general population the patients' HRQoL reached. Moreover, this study provided the EQ-5D index, which could be used as a utility score to assess the efficiency of intervention programs provided to breast cancer survivors in future work. This would help us to design the prospective tailored HRQoL intervention programs that support breast cancer survivors according to time from operation and provide basic information to combine new technologies and conventional study of HRQoL by using diverse instruments such as mobile and wearable devices to monitor the HRQoL of breast cancer survivors.

\section{Conclusions}

This study was a cross-sectional survey at one healthcare system vs. national survey for general population.

Although breast cancer survivors had a low EQ-5D index at an early stage after surgery, the index changed over time, eventually index of breast cancer survivors over 5 years after surgery showed similar to the age-matched general population group. However, the HRQoL level of the breast cancer group even over 5 years after surgery in the pain and psychological aspect was still lower than that of the age-matched general population group, even though the HRQoL of the physical area was similar to that of the general population. Therefore, to improve the HRQoL of breast cancer patients, tailored intervention programs that depend on time after surgery and dimension should be designed. This study also provides data for assessing the efficiency of such tailored HRQoL intervention programs. Prospective large-scale cohort studies of breast cancer survivors are needed to provide definite evidence to define the factor(s) affecting HRQoL according to time and to investigate the benefits of tailored interventions.

\section{Abbreviations}

EQ-5D-3 L: EuroQoL five-dimension three-level questionnaire; HRQoL: Healthrelated quality of life; KNHANES: Korea Health and Nutrition Examination Survey

\section{Funding}

This study was funded by a grant (grant no 2012-0510/2013-0510) from the Asan Institute for Life Science, Asan Medical Center, Seoul, Korea.

\section{Availability of data and materials}

The datasets used and analysed during the current study are available from the corresponding author on reasonable request.

\section{Authors' contributions}

JY was responsible for the data collection and drafted the manuscript, working under the direct supervision of JWL and M-WJ. W-SS and M-WJ were responsible for the statistics and corrected the draft. JWL, W-SS, M-WJ, SBL, II YC, BHS, and S-HA read and corrected the draft versions of the manuscript. All authors read and approved the final manuscript.

\section{Ethics approval and consent to participate}

This study was approved by the Institutional Review Board of Asan Medical Center. Informed consent was obtained from all participants.

\section{Consent for publication}

Not applicable

\section{Competing interests}

The authors declare that they have no competing interests.

\section{Publisher's Note}

Springer Nature remains neutral with regard to jurisdictional claims in published maps and institutional affiliations.

\author{
Author details \\ 'Division of Breast Surgery, Department of Surgery, Samsung Medical Center, \\ Sungkyunkwan University School of Medicine, Seoul 06531, South Korea. \\ ${ }^{2}$ Department of Preventive Medicine, University of Ulsan College of \\ Medicine, 86 Asanbyeongwon-gil, Songpa-gu, Seoul 138-736, South Korea. \\ ${ }^{3}$ Department of Surgery, University of Ulsan College of Medicine, Asan \\ Medical Center, 86 Asanbyeongwon-gil, Songpa-gu, Seoul 138-736, South \\ Korea.
}

Received: 26 October 2017 Accepted: 2 July 2018

Published online: 20 July 2018

References

1. Ferlay J, Soerjomataram I, Ervik M, Dikshit R, Eser S, Mathers C, Rebelo M, Parkin DM, Forman D, Bray, F.: GLOBOCAN 2012 v1.0, Cancer Incidence and Mortality Worldwide: IARC CancerBase No. 11. 2012.

2. Arndt V, Merx H, Stegmaier C, Ziegler H, Brenner H. Persistence of restrictions in quality of life from the first to the third year after diagnosis in women with breast cancer. J Clin Oncol. 2005;23:4945-53.

3. Ganz PA, Guadagnoli E, Landrum MB, Lash TL, Rakowski W, Silliman RA. Breast cancer in older women: quality of life and psychosocial adjustment in the 15 months after diagnosis. J Clin Oncol. 2003;21:4027-33.

4. Trentham-Dietz A, Sprague BL, Klein R, Klein BE, Cruickshanks KJ, Fryback DG, Hampton JM. Health-related quality of life before and after a breast cancer diagnosis. Breast Cancer Res Treat. 2008;109:379-87.

5. Koch L, Jansen L, Herrmann A, Stegmaier C, Holleczek B, Singer S, Brenner $\mathrm{H}$, Arndt V. Quality of life in long-term breast cancer survivors - a 10-year longitudinal population-based study. Acta Oncol. 2013;52:1119-28.

6. Arndt $\mathrm{V}$, Stegmaier $\mathrm{C}$, Ziegler $\mathrm{H}$, Brenner $\mathrm{H}$. Quality of life over 5 years in women with breast cancer after breast-conserving therapy versus mastectomy: a population-based study. J Cancer Res Clin Oncol. 2008;134:1311-8.

7. Browall M, Ostlund $\mathrm{U}$, Henoch I, Wengstrom $Y$. The course of health related quality of life in postmenopausal women with breast cancer from breast surgery and up to five years post-treatment. Breast. 2013;22:952-7.

8. Ganz PA, Greendale GA, Petersen L, Kahn B, Bower JE. Breast cancer in younger women: reproductive and late health effects of treatment. J Clin Oncol. 2003;21:4184-93.

9. King MT, Kenny P, Shiell A, Hall J, Boyages J. Quality of life three months and one year after first treatment for early stage breast cancer: influence of treatment and patient characteristics. Qual Life Res. 2000;9:789-800.

10. Ahn SH, Park BW, Noh DY, Nam SJ, Lee ES, Lee MK, Kim SH, Lee KM, Park SM, Yun YH. Health-related quality of life in disease-free survivors of breast cancer with the general population. Ann Oncol. 2007;18:173-82.

11. van der Steeg AF, De Vries J, van der Ent FW, Roukema JA. Personality predicts quality of life six months after the diagnosis and treatment of breast disease. Ann Surg Oncol. 2007;14:678-85. 
12. Hsu T, Ennis M, Hood N, Graham M, Goodwin PJ. Quality of life in long-term breast cancer survivors. J Clin Oncol. 2013;31:3540-8.

13. Neyt $M$, Albrecht J. The long-term evolution of quality of life for disease-free breast cancer survivors: a comparative study in Belgium. J Psychosoc Oncol. 2006;24:89-123.

14. Ganz PA, Desmond KA, Leedham B, Rowland JH, Meyerowitz BE, Belin TR. Quality of life in long-term, disease-free survivors of breast cancer: a followup study. J Natl Cancer Inst. 2002;94:39-49.

15. Fischer U, Anca D, Arnold M, Nedeltchev K, Kappeler L, Ballinari P, Schroth G, Mattle HP. Quality of life in stroke survivors after local intra-arterial thrombolysis. Cerebrovasc Dis. 2008;25:438-44.

16. EuroQol G. EuroQol-a new facility for the measurement of health-related quality of life. Health Policy. 1990;16:199-208.

17. Solli O, Stavem K, Kristiansen IS. Health-related quality of life in diabetes: the associations of complications with EQ-5D scores. Health Qual Life Outcomes. 2010;8:18.

18. Hong JY, Kim SY, Chung KS, Kim EY, Jung JY, Park MS, Kang YA, Kim SK, Chang J, Kim YS. Factors associated with the quality of life of Korean COPD patients as measured by the EQ-5D. Qual Life Res. 2015;24:2549-58.

19. Kwon KM, Lee JS, Jeon NE, Kim YH. Factors associated with health-related quality of life in Koreans aged over 50 years: the fourth and fifth Korea National Health and nutrition examination survey. Health Qual Life Outcomes. 2017;15:243.

20. Testa MA, Simonson DC. Assesment of quality-of-life outcomes. N Engl J Med. 1996;334:835-40.

21. Kim SH, Jo MW, Lee JW, Lee HJ, Kim JK. Validity and reliability of EQ-5D-3L for breast cancer patients in Korea. Health Qual Life Outcomes. 2015;13:203.

22. Dolan P. Modeling valuations for EuroQol health states. Med Care. 1997;35:1095-108.

23. Shaw JW, Johnson JA, Coons SJ. US valuation of the EQ-5D health states: development and testing of the D1 valuation model. Med Care. 2005;43:203-20.

24. Tsuchiya A, Ikeda S, Ikegami N, Nishimura S, Sakai I, Fukuda T, Hamashima C, Hisashige A, Tamura M. Estimating an EQ-5D population value set: the case of Japan. Health Econ. 2002;11:341-53.

25. Lee YK, Nam HS, Chuang LH, Kim KY, Yang HK, Kwon IS, Kind P, Kweon SS, Kim YT. South Korean time trade-off values for EQ-5D health states: modeling with observed values for 101 health states Value Health. 2009:12:1187-93.

26. Stover AM, Mayer DK, Muss H, Wheeler SB, Lyons JC, Reeve BB. Quality of life changes during the pre- to postdiagnosis period and treatment-related recovery time in older women with breast cancer. Cancer. 2014;120:1881-9.

27. Tsiplova K, Pullenayegum E, Cooke T, Xie F. EQ-5D-derived health utilities and minimally important differences for chronic health conditions: 2011 Commonwealth Fund survey of sicker adults in Canada. Qual Life Res. 2016;25:3009-16.

28. Pickard AS, Neary MP, Cella D. Estimation of minimally important differences in EQ-5D utility and VAS scores in cancer (vol 5, pg 70, 2007). Health Qual Life Outcomes. 2010;8:4.

29. Tchen N, Juffs HG, Downie FP, Yi QL, Hu H, Chemerynsky I, Clemons M, Crump M, Goss PE, Warr D, et al. Cognitive function, fatigue, and menopausal symptoms in women receiving adjuvant chemotherapy for breast cancer. J Clin Oncol. 2003;21:4175-83.

30. Mols F, Vingerhoets AJJM, Coebergh JW, Vande poll-Franse LV. Quality of life among long-term breast cancer survivors: a systematic review. Eur J Cancer. 2005;41:2613-9.

31. Phillips SM, McAuley E. Associations between self-reported post-diagnosis physical activity changes, body weight changes, and psychosocial wellbeing in breast cancer survivors. Support Care Cancer. 2015;23:159-67.

32. Mishra SI, Scherer RW, Snyder C, Geigle PM, Berlanstein DR, Topaloglu O. Exercise interventions on health-related quality of life for people with cancer during active treatment. Cochrane Database Syst Rev. 2012:8:CD008465.

Ready to submit your research? Choose BMC and benefit from:

- fast, convenient online submission

- thorough peer review by experienced researchers in your field

- rapid publication on acceptance

- support for research data, including large and complex data types

- gold Open Access which fosters wider collaboration and increased citations

- maximum visibility for your research: over $100 \mathrm{M}$ website views per year

At BMC, research is always in progress.

Learn more biomedcentral.com/submissions 